\title{
CÉLULAS MASTÓIDEAS: REVISÃO ANATOMOFUNCIONAL
}

\author{
MASTOID CELLS: ANATOMOFUNCTIONAL REVIEW
}

Patricia T. Tavano ${ }^{1}$, Valdemir R. Pereira ${ }^{2}$

\begin{abstract}
${ }^{1}$ Mestranda em Educação, Faculdade de Educação - USP/SP. Especialista em Diagnóstico por Imagem: ênfase anatômica - Centro Universitário São Camilo/SP. Docente em Anatomia Humana e Anatomia Aplicada - Faculdade Comunitária de Taubaté - Anhanguera Educacional. ${ }^{2}$ Mestre em Morfologia, UNIFESP/SP. Docente em Anatomia Humana e Anatomia em Imagens dos cursos de Graduação e Pós graduação do Centro Universitário São Camilo.

Correspondência: Patricia T. Tavano. Av. José Olegário de Barros, 46 - Taubaté / SP. (patrícia @ tavano.net)
\end{abstract}

Tavano PT, Pereira VR. Células mastóideas: revisão anatomofuncional. Medicina (Ribeirão Preto) 2008; 41 (4): 491-6.

RESUMO: Modelo do estudo: revisão bibliográfica.

Objetivo(s) do estudo: ampliar os conhecimentos sobre o desenvolvimento e pneumatização do osso temporal, bem como compreender a distribuição pelo osso das células mastóideas com suas características etárias e sexuais.

Metodologia: revisão bibliográfica baseada nos principais indexadores científicos (PUBLIMED, MEDLINE, BIREME, SCIELO) com recorte de publicações dos últimos 20 anos e com suporte das descrições consagradas dos tratados sobre Anatomia Humana.

Conclusões: o desenvolvimento das células mastóideas inicia-se intra-útero e geralmente é completado durante os cinco primeiros anos de vida, podendo continuar até a segunda década. Pode ser influenciado por diversos fatores que causam variações na pneumatização final do adulto, entre eles os mais primordiais são os comprometimentos patológicos da orelha média durante a infância, os fatores ambientais e o código genético individual. É pouco expressiva a diferença sexual e as assimetrias bilaterais entre os grupos, sendo a quantificação volumétrica um dado de difícil obtenção. A concentração das cavidades é maior no processo mastóide, mas comumente estende-se ao ápice petroso. O conhecimento real da pneumatização, distribuição e variáveis das células mastóideas ainda não atingiu um estágio final, necessitando de mais estudos com metodologia única e cortes maiores para que acordos possam ser alcançados.

Descritores: Osso Temporal. Processo Mastóide. Células Mastóideas. Anatomia.

\section{1- INTRODUÇÃO}

O osso temporal está localizado na região lateral do crânio e pode ser dividido em cinco partes: escamosa, petrosa, timpânica, estilóidea e mastóidea. Em sua porção mastóidea, encontram-se inúmeras cavidades aeradas, as células mastóideas. ${ }^{1-5}$

As células mastóideas apresentam-se como uma série de cavidades preenchidas por ar que se interconectam e surgem como um divertículo da cavi- dade timpânica a partir do antro mastóide ${ }^{2,6,7}$. Diversas funções estão associadas a estas cavidades, sendo relatadas: recepção de som, isolamento acústico, proteção das estruturas auditivas contra violência externa, redução do peso do crânio e reservatório aéreo da orelha média ${ }^{7-10}$.

Embriologicamente, estas células começam a se formar posteriormente ao recesso epitimpânico ao redor da vigésima segunda semana gestacional. $\mathrm{O}$ antro mastóide está pronto ao final da vida fetal, sendo forma- 
do pela expansão da cavidade timpânica em torno da trigésima quarta semana ${ }^{2,11-14}$. Esta cavidade tem aproximadamente o tamanho que terá no adulto ao nascimento, mas ainda não há células macroscópicas. ${ }^{8,15}$

As células mastóideas se desenvolvem a partir do nascimento e podem ser visualizadas ao redor do segundo ano de vida. O adequado desenvolvimento destas células estaria relacionado à: aspectos genéti$\cos ^{8,10,12,16}$, grau de envolvimento patológico da orelha média durante a infância ${ }^{7,8,10,12,13,15}$, tamanho do crânio e estatura do indivíduo ${ }^{7}$, funcionamento da tuba auditiva $^{7,8}$ e fatores ambientais ${ }^{8,16}$.

Virapongse et al. ${ }^{8}$ relatam que a formação dos espaços ósseos precede a epitelização e aeração das células mastóideas. Originalmente, estas cavidades contêm medula óssea que sofre um processo de desdiferenciação em tecido conjuntivo frouxo e atrofia após a invaginação da mucosa, formando uma fina membrana residual aderida ao periósteo. O processo se encerra com o alargamento das cavidades. Aparentemente, essa fase ocorre apenas na presença de ar, ou seja, após o nascimento.

Isono et al ${ }^{12}$ propõem que as diferenças na formação das células mastóideas são possivelmente relacionadas com as regiões em que se encontram, pois cada região apresenta um metabolismo ósseo distinto após o nascimento, levando a variação morfológica. $\mathrm{O}$ metabolismo pode ser dividido em cartilaginoso e fibroso, sendo o último mais propenso a inflamações, ponto que levaria ao comprometimento do volume aéreo total.

Os estudos antropológicos de Balzeau et al ${ }^{17}$ propõem que a pneumatização seria um fenômeno oportunista. As cavidades se estenderiam por todo o espaço da superfície óssea que apresentasse reabsorção desde que mantivesse a resistência suficiente, propagando-se de acordo com o espaço disponível e com as restrições encontradas, invadindo o processo mastóide, a escama, e outras áreas, sendo limitada pelas estruturas circundantes. Com o desenvolvimento lateral dos lobos parietal e temporal e a individualização das eminências cerebrais parietais, a conformação craniana lateral e basal se modificaria, o que levaria a restrições diferentes na superfície do osso temporal e ao alinhamento vertical da escama. Estas variações restringiriam a expansão das células mastóideas à frente da escama e do processo mastóide e modificariam a conformação externa do osso.

O desenvolvimento das células mastóideas e sua pneumatização alteram o tamanho e formato do osso temporal. A pneumatização agiria como expan- sora, levando o osso à convexidade e o processo mastóide ao formato mais triangular, entretanto, células ebúrneas (não aeradas) não comprometeriam o formato do osso. A distribuição destas células dentro do osso temporal é mais comumente concentrada no processo mastóide, no entanto os estudos mostram que elas podem atingir a região petrosa, a escama, e mesmo o processo zigomático do temporal ${ }^{5,8,15}$.

Este estudo teve por objetivos ampliar os conhecimentos sobre o desenvolvimento e pneumatização do osso temporal, bem como compreender a distribuição pelo osso das células mastóideas com suas características etárias e quanto ao sexo, centrandonos na descrição anatômica destas cavidades, no intuito de aprofundar o entendimento que se tem destas.

\section{2- METODOLOGIA}

Este estudo constou de uma revisão bibliográfica sobre o tema abordado, baseada nos principais indexadores científicos, a saber, Publimed, Medline, Bireme, Scielo com recorte de publicações nos últimos 20 anos sobre o tema, e com suporte das descrições consagradas dos tratados sobre Anatomia $\mathrm{Hu}$ mana.

A bibliografia específica selecionada para o tema foi utilizada levando-se em consideração as datas de publicação em ordem crescente dos artigos, no intuito de acompanhar a evolução dos estudos realizados.

\section{3- ANÁlISE COMPARATIVA DAS CÉLULAS MASTÓIDEAS}

O estudo das células mastóideas gera algumas controvérsias. Os autores fazem relatos discordantes em diversos aspectos. Vemos que quanto ao desenvolvimento, às diferenças sexuais, a simetria bilateral, o volume, a área geral e as taxas de pneumatização há muitos desencontros.

É fato reconhecido e relatado por eles a importância de processos patológicos da orelha média como comprometedores do desenvolvimento e pneumatização das células mastóideas. Todos os autores comentam que a presença de patologias na infância reflete em redução de aeração adulta, podendo levar à hipopneumatização.

Outro ponto de consenso das teorias sobre o desenvolvimento é que o código genético, os fatores ambientais e a tuba auditiva também interfeririam na aeração mastóidea. 
Alterações da tuba auditiva, como bloqueios e más formações, são citados pelos autores como responsáveis por um possível aumento de pneumatização em um mecanismo compensatório para reduzir a possibilidade de formação de pressão negativa na cavidade timpânica que conduziria à retração da membrana timpânica. Este mecanismo compensatório, descrito por Virapongse et $\mathrm{al}^{8}$ e por Görür et $\mathrm{al}^{18}$,é apenas citado superficialmente nos outros autores. Interessante notar que, no estudo de Sethi et $\mathrm{al}^{7} 50 \%$ dos indivíduos com bloqueios da tuba auditiva apresentaram pneumatização pobre e os outros $50 \%$ boa pneumatização, sendo que os indivíduos com tuba auditiva livre apresentaram apenas $44 \%$ de boa pneumatização contra $54 \%$ de baixa pneumatização. Uma contraposição notável aos outros estudos.

As determinações genéticas para pneumatização mastóidea são relacionadas à facilidade de desenvolvimento de patologias da orelha média. Em Isono et al ${ }^{12}$ encontramos uma explicação interessante quanto à importância do metabolismo fibroso, propenso a processos inflamatórios, e as alterações na aeração das cavidades.

Os fatores ambientais são citados, mas não explicados adequadamente. Ao organizarmos os dados dos diversos autores, podemos aludir a alterações no ambiente que fragilizariam o indivíduo, predispondo-o a processos inflamatórios, como comentam Lee et $\mathrm{al}^{10}$ sobre os fatos históricos de seu país*

Balzeau et $\mathrm{al}^{17}$ nos trazem elementos antropológicos, visto que a evolução hominídea estaria relacionada às necessidades de adaptação ao ambiente. Estas necessidades refletiriam em adaptações neurológicas que conduziriam ao aumento do volume nervoso no endocrânio, reduzindo o espaço para aeração temporal. Nos dias atuais, estas alterações ambientais, estariam, talvez, ligadas aos aspectos médiconutricionais citados por Lee et $\mathrm{al}^{10}$.

A distribuição das células mastóideas pelo osso temporal é quantificada apenas em Virapongse et al8 e em Yamakami et $a^{15}$, que estabelecem valores semelhantes para pneumatização do processo mastóide. Os outros autores relatam que a extensão e distribuição das cavidades é variável, com preferência de concentração no processo mastóide.
O Quadro I foi organizado com os dados extraídos dos estudos analisados, e sintetiza as diferenças encontradas na análise das células mastóideas.

Podemos observar que as concordâncias entre os autores não são constantes. Como cada estudo possui objetivos específicos distintos, então vários aspectos não são verificados em todos eles e foram categorizados como não relata, assim faltam alguns parâmetros de comparação.

A simetria bilateral, aspecto que estabelece se a distribuição das células mastóideas é simétrica em um mesmo indivíduo considerando-se seu lado direito e o esquerdo, é pouco dissonante. Sirikçi et a ${ }^{19}$ faz um estudo comparativo entre orelhas patológicas e orelhas saudáveis, assim há assimetria pela própria presença de patologia. Virapongse et $\mathrm{al}^{8}$ e Yamakami et al $^{15}$ relatam achados de simetria de $72 \%$ a $98 \%$ e 98\% respectivamente, ficando em um intervalo até certo ponto semelhante. Lee et $\mathrm{a}^{10}$ estabelecem que há simetria mas não cita a porcentagem exata encontrada, já Karakas et al ${ }^{16}$ dizem que há assimetria de em média $0,4 \% \mathrm{~cm}^{3}$, dado categorizado pelos autores como estatisticamente significante.

Nas diferenças quanto ao sexo, aspecto que determina se há diferença de aeração entre células mastóideas femininas e masculinas, vemos que apenas Karakas et $\mathrm{al}^{16}$ observam diferenças entre os sexos estatisticamente significativa entre as células mastóideas. Virapongse et al8, Yamakami et al ${ }^{15}$ e Lee et $\mathrm{al}^{10}$ não encontraram tais diferenças.

O volume e a área geral, ou seja, a extensão da pneumatização é um dos pontos de maior dificuldade relatados pelos autores para quantificação. Para Isono et $\mathrm{al}^{12} \mathrm{o}$ volume médio foi de $5,97 \mathrm{ml}$, para Lee et $\mathrm{al}^{10} 7,09 \mathrm{~cm}^{3}$ e para Karakas et al ${ }^{16}$ praticamente o dobro, $14,05 \mathrm{~cm}^{3}$. Se considerarmos as margens de erro, vemos que Isono et $\mathrm{al}^{12}$ e Lee et $\mathrm{al}^{10}$ seriam bastante próximos, se distanciando bastante de Karakas et al $^{16} * *$. Porém, ao compararmos estes autores a Sirikçi et al ${ }^{19}$ vemos que o volume é quase o dobro em relação a Karakas et al $^{16}$ e quase o quádruplo quanto ao estudo de Isono et $\mathrm{al}^{12}$ e Lee et $\mathrm{al}^{10}$.

$\mathrm{Na}$ quantificação de área, Sethi et $\mathrm{al}^{7}$ relata a área de $10,8 \mathrm{~cm}^{2}$ enquanto Sirikçi et al ${ }^{19}$ observaram variação de $3,5 \mathrm{~cm}^{2}$ a $3,7 \mathrm{~cm}^{2}$, valor bastante inferior ao anterior.

\footnotetext{
* Os autores estabelecem uma ressalva, relacionando a redução de volume acentuada a partir da sétima década de vida dos indivíduos pesquisados ao período histórico de guerras no país de origem (a Coréia). As guerras levariam a um comprometimento médiconutricional dos sujeitos em sua época, com possíveis interferências nos resultados atuais ${ }^{10}$.

** $1 \mathrm{ml}$ é equivalente a $1 \mathrm{~cm}^{3}$. Conferir em http://www.ipem.sp.gov.br, no link conversor de unidades.
} 
Quadro 1: Comparação dos dados sobre as células mastóideas de acordo com diversos autores.

\begin{tabular}{|c|c|c|c|c|c|}
\hline Autores & $\begin{array}{l}\text { Simetria } \\
\text { bilateral }\end{array}$ & $\begin{array}{l}\text { Diferenças } \\
\text { sexuais }\end{array}$ & $\begin{array}{l}\text { Volume } \\
\text { área geral }\end{array}$ & Pneumatização & $\begin{array}{l}\text { Volume máximo } \\
\text { atingido }\end{array}$ \\
\hline Virapongse et $\mathrm{al}^{8}$ & $72 \%$ a $99 \%$ & não & não relata & $\begin{array}{l}\text { 12\% ebúrnea } \\
88 \% \text { boa }\end{array}$ & à partir de 5 anos \\
\hline Wong et al ${ }^{9}$ & não relata & não relata & não relata & $75 \%$ boa & não relata \\
\hline Yamakami et al $^{15}$ & $98 \%$ & não & não relata & $\begin{array}{l}\text { 11\% ebúrnea } \\
89 \% \text { boa }\end{array}$ & não relata \\
\hline Isono et al ${ }^{12}$ & não relata & não relata & $5,97 \mathrm{ml}$ & não relata & 14-15 anos \\
\hline Sirikçi et al ${ }^{19}$ & $\begin{array}{l}\text { orelha patológica } \\
\text { X orelha sadia }\end{array}$ & não relata & $\begin{array}{l}\text { vol: } 22,9 \mathrm{~cm}^{3} \text { a } 27,9 \mathrm{~cm}^{3} \\
\text { área: } 3,5 \mathrm{~cm}^{2} \text { a } 3,7 \mathrm{~cm}^{2}\end{array}$ & não relata & não relata \\
\hline Lee et al ${ }^{10}$ & $\operatorname{sim}$ & não & $7,095 \mathrm{~cm}^{3}$ & não relata & $3^{a}$ década \\
\hline Karakas et al ${ }^{16}$ & $\begin{array}{c}7,40 \mathrm{~cm}^{3} \text { à direita } \\
7,0 \mathrm{~cm}^{3} \text { à esquerda }\end{array}$ & $\operatorname{sim}$ & $14,05 \mathrm{~cm}^{3}$ & não relata & $3^{a}$ década \\
\hline Sethi et $\mathrm{al}^{7}$ & não relata & não relata & $10,8 \mathrm{~cm}^{3}$ & $\begin{array}{l}\text { 16\% ebúrnea } \\
84 \% \text { boa }\end{array}$ & não relata \\
\hline Görür et al 18 & não relata & não relata & não relata & não relata & 8-9 anos \\
\hline
\end{tabular}

Fontes: Virapongse et $\mathrm{al}^{8}$, 1985; Wong et $\mathrm{a}^{19}$ 1999; Yamakami et al ${ }^{15}, 2003$; Isono et $\mathrm{a}^{112}, 2003$; Sirikçi et al ${ }^{19}, 2004$; Lee et al ${ }^{10}, 2005$; Karakas et al ${ }^{16}, 2005$; Sethi et $\mathrm{al}^{7}, 2006$; Görür et $\mathrm{al}^{18}, 2006$

Importante notar que os dados de Sirikçi et al ${ }^{19}$ foram obtidos em indivíduos com presença de patologia da orelha média, e afirmam que a presença de uma patologia altera a aeração das células mastóideas, assim, mesmo que esses dados colocados na tabela comparativa sejam referentes ao lado saudável, é preciso cautela. Ao compararmos os estudos vemos que a área de Sirikçi et al $^{19}$ é menor em relação à de Sethi et $\mathrm{al}^{7}$; porém o volume relatado por Sirikçi et a ${ }^{19}$ é maior que os demais, de $22,9 \mathrm{~cm}^{3}$ a $27,9 \mathrm{~cm}^{3}$.

Quanto à pneumatização das células mastóideas, a quantidade de células aeradas, os autores chegam a valores mais concordantes. Virapongse et al8, Yamakami et a ${ }^{15}$ e Sethi et al ${ }^{7}$ relatam valores próximos, de $84 \%$ a $89 \%$ de boa pneumatização. Porém, Wong et $\mathrm{al}^{9}$ apresentam valores pouco menores de $75 \%$ de boa pneumatização.

O aspecto volume máximo atingido reflete a idade final de desenvolvimento das células mastóideas a partir da qual o máximo volume de aeração estaria completado. O desenvolvimento (intra-útero e pósparto) das células mastóideas não é completamente compreendido, deixando várias lacunas, o que se reflete em idades muito variáveis entre os autores. Observamos que no estudo de Virapongse et $\mathrm{al}^{8}$, propõem o final do desenvolvimento aproximadamente aos cinco anos de idade. Isono et $\mathrm{al}^{12}$, concluem que o desenvolvimento continuaria até a puberdade, com alguns indivíduos atingindo-o aos 4-6 anos, em acordo com o predecessor. Lee et al ${ }^{10}$ e Karakas et al ${ }^{16}$ apresentam um desenvolvimento continuado até a terceira década de vida, mas Görür et al ${ }^{18}$ relatam que ele cessaria aos 8-9 anos, aproximando-se de Isono et al ${ }^{12}$.

As variações nos dados dos estudos podem estar associadas a diversos aspectos, que são aventados pelos próprios autores como os próprios fatores do desenvolvimento das células. Assim, o ambiente, as alterações patológicas (um dos aspectos mais assinalados), o comprometimento da tuba auditiva, as determinações genéticas, as variações ambientais fariam com que populações distintas apresentassem células mastóideas distintas.

Outro ponto a ser assinalado é a variação dos métodos, das técnicas e tecnologias adotadas para obtenção dos dados. Alguns autores utilizaram exclusivamente indivíduos sem comprometimento patológico das células mastóideas, outros propuseram estudos comparativos.

Uma vez que acessar as células in vivo é um método indireto, as variações de volumes, áreas, 
pneumatização, acabam sendo muito diferentes. Assim, o estudo das células mastóideas do osso temporal enfrenta problemas relacionados à sua própria anátomo-funcionabilidade que nem sempre podem ser contornados.

\section{4- CONSIDERAÇÕES FINAIS}

Os autores relatados nesta revisão não convergem em uma única posição.

Há estudos que determinam invariância quanto ao sexo, e há estudos que estabelecem distinções entre mastóides masculinas e femininas; há estudos que estabelecem diferença pouco significativa na simetria lateral, outros relatam variações. A maior parte dos pesquisadores considera pouco significativa as diferenças quanto ao sexo e assimetrias.

Estes dois pontos, somados ao volume do complexo de células mastóideas são as maiores polêmicas encontradas na execução deste estudo.
Alguns aspectos sobre os volumes devem ser considerados: os próprios autores relatam dificuldades na quantificação volumétrica, dadas as variações individuais, assim, os softwares de reconstrução e volumetria teriam de lidar com muitas variáveis; o aspecto ambiental de desenvolvimento das células, que não é aceito por unanimidade, mas que parece contribuir nas variações; e a determinação genética.

Se somarmos estes pontos, vemos que existiria a tendência a divergências entre as várias nacionalidades retratadas pelos autores, pois histórias diferentes bem como códigos genéticos diferentes fazem com que a conformação corporal se modifique e porque não aspectos morfológicos das células mastóideas.

Assim, o conhecimento real da pneumatização, distribuição e variáveis das células mastóideas ainda não atingiu um estágio final. Mais estudos com metodologia uniforme e amostras mais amplas se fazem necessários para que acordos possam ser alcançados.

Tavano PT, Pereira VR. Mastoid cells: anatomofunctional review. Medicina (Ribeirão Preto) 2008; 41 (4): 491-6.

ABSTRACT: Research model: bibliography reviewing. Intends: maximize the knowledge about the development and pneumatization of the temporal bone, understanding the mastoid air cells distribution over the bone, regarding sexual and ages characteristics.

Metodologic: reviewing the available bibliography on the last twenty years at the main scientific indexes: PUBMED, MEDLINE, BIREME, SCIELO, supported by well-know Human Anatomy agreements.

Conclusions: We concluded that mastoid air cells development starts intra-uterus and usually ends at the first five years of life, but may last until the twenties. It may be influenced by several factors that vary the adult pneumatization, including pathological condition of medium ear at infantry and by environmental variation and different genetic code. We do not find relevance in gender nor in bilateral asymmetries, even if it is hard to quantify such differences in the reviewed studies. The cavity concentration is higher at the mastoid process, but usually deploys up to the petrous apex. The real knowledge about pneumatization, distribution and variable mastoid air cells has not reach a final status needed for further investigation following uniform and larger samples.

Uniterms: Temporal Bone. Mastoid. Mastoid cells. Anatomy.

\section{REFERÊNCIAS BIBLIOGRÁFICAS}

1 - Gardner E; Gray DJ; O’Rahilly R. Anatomia: estudo regional do corpo humano. 4ed. Rio de Janeiro: Guanabara Koogan, 1988.

2 - Latarjet M; Liard AR; Liard AR. Anatomia Humana. 2 ed. São Paulo: Panamericana, 1996.
3 - Gray H. Anatomy of the Human Body. Philadelphia: Lea \& Febiger, 1918; Bartleby.com, 2000. Disponível em www.bartleby.com/107/. Acesso em 22/08/2006.

4 - Dangelo JG; Fattini CA. Anatomia Humana sistêmica e segmentar. 3ed. São Paulo: Atheneu, 2007.

5 - Didio LJA. Tratado de Anatomia sistêmica aplicada. 2 ed. São Paulo: Atheneu, 2002. 
6 - Ellis H. Anatomia clínica. 9ed. Rio de Janeiro: Guanabara Koogan, 1999.

7 - Sethi A. et al. Pneumatization of mastoid cells: role of acquired factors. Int J Morphol 2006; 24 (1): 35-8.

8 - Virapongse C; Sarwar M; Bhimani S; Sasaki C; Shapiro R. Computed tomography of temporal bone pneumatization: 1 . normal pattern and morphology. Am J Roentgenol 1985; 145: 473-81.

9 - Wong K.; Munk PL. Magnetic Ressonance imaging of the temporomandibular joint: diagnostic difficulty caused by extensive pneumatization of the mastoid air cells. Skeletal Radiol 1999; 28: 577-80.

10 - Lee DH; Jun BC; Kim DG; Jung MK; Yeo SW. Volume variation of mastoid pneumatization in different age groups: a study by three-dimensional reconstruction based on computed tomography images. Surg Radiol Anat (Seoul) 2005; 27: 3742.

11 - Lindner LB. O feto como ser ouvinte. Porto Alegre, 1999. [Monografia de conclusão do curso de especialização em Audiologia Clínica] Disponível em http://www.cefac.br/library/ teses. Acesso em 15/03/2005.

12 - Isono M; Ito A; Nakayama K; Myiashita H; Saito K; Murata K. Computed assessment of developmental changes in the mastoid air cells system. International Congress Series (Osaka) 2003; 1254: 487-91.

13 - Herrerias de Campos CA; Olival Costa HO Tratado de otorrinolaringologia. São Paulo: Roca, 2003. p. 377-81.
14 - Moore KL; Persaud TVN.. Embriologia clínica. 7 ed. Rio de Janeiro: Elsevier, 2004. p.-520-1.

15 - Karakas S; Kavakli A. Morphometric examination of the paranasal sinuses and mastoid air cells using computed tomography. Ann Saudi Med 2005; 25 (1): 41-5.

16 - Yamakami I; Uchino Y; Kobayashi E; Yamamura A. Computed tomography evaluation of air cells in the petrous bone. Neurol Med Chir (Tokyo) 2003; 43: 334-9.

17 - Balzeau A; Grimaud-Hervé D. Cranial base morphology and temporal bone pneumatization in Asian Homo Erectus. J. hum. evol. doi: 10.1016/j.jhevol. 2006.04.007.

18 - Görür K; Özcan C; Talas DÜ. The computed tomographical and tympanometriocal evaluation of mastoid pneumatization and attic blockage in patients with chronic otitis media with effusion. Int J Pediatr Otorhinolaryngol 2006; 70: 481-5.

19 - Sirikçi A; Bayazit YA; Kervancioglu S; Ozer E; Kanlikama M; Bayrani M. Assessment of mastoid air cell size versus sigmoid sinus variables with a tomography-assisted digital image processing program and morphometry. Surg. Radiol Anat 2004; 26: 145-8.

Recebido para publicação em 18/06/2008

Aprovado para publicação em 22/10/2008 